Article (refereed) - postprint

Curtis, R.J.; Isaac, N.J.B. 2015. The effect of temperature and habitat quality on abundance of the Glanville fritillary on the Isle of Wight: implications for conservation management in a warming climate. Journal of Insect Conservation, 19 (2). 217-225. 10.1007/s10841-014-9738-1

(C) Springer International Publishing Switzerland 2014

This version available http://nora.nerc.ac.uk/509086/

NERC has developed NORA to enable users to access research outputs wholly or partially funded by NERC. Copyright and other rights for material on this site are retained by the rights owners. Users should read the terms and conditions of use of this material at

http://nora.nerc.ac.uk/policies.html\#access

This document is the author's final manuscript version of the journal article, incorporating any revisions agreed during the peer review process. Some differences between this and the publisher's version remain. You are advised to consult the publisher's version if you wish to cite from this article.

The final publication is available at Springer via http://dx.doi.org/10.1007/s10841-014-9738-1

Contact CEH NORA team at noraceh@ceh.ac.uk

The NERC and CEH trademarks and logos ('the Trademarks') are registered trademarks of NERC in the UK and other countries, and may not be used without the prior written consent of the Trademark owner. 


\title{
The Effect of Temperature and Habitat Quality on Abundance of the Glanville fritillary on the Isle of Wight: Implications for Conservation Management in a Warming Climate.
}

\author{
Authors: Curtis, R.J. ${ }^{1,2,3,4}$ \& Isaac, N.J.B. ${ }^{1}$
}

${ }^{1}$ NERC Centre for Ecology \& Hydrology, Maclean Building, Crowmarsh Gifford, Wallingford, OX10 8BB, UK

${ }^{2}$ University College London, Gower Street, London, WC1E 6BT, UK

${ }^{3}$ Institute of Zoology, Zoological Society of London, Regent's Park, London, NW1 4RY, UK

${ }^{4}$ Present address: Environment and Sustainability Institute, University of Exeter, Penryn Campus Penryn, Cornwall TR10 9FE, UK

Keywords: Melitaea cinxia, abundance, habitat quality, temperature, butterflies, hostplants.

\begin{abstract}
Creating variation in microclimates through habitat management is often advocated as a way of ameliorating the impact of climate warming, although the effectiveness of microclimate management has rarely been studied.

We compared temporal variation in habitat quality (the availability of suitably warm microclimates) and ambient air temperature on the abundance of a highly thermophilous species of butterfly, the Glanville fritillary Melitaea cinxia, at one site on the south coast of the Isle of Wight, UK, from 1997 2010. Ground temperatures beneath the various habitat successional stages were measured and compared, and the relationship between butterfly abundance and hostplant and weather variables was examined.

Temporal variation in habitat quality was almost twice as strong as a predictor of butterfly abundance as ambient air temperature. We found no relationship between abundance and rainfall.
\end{abstract}


Comparisons of ground temperatures beneath habitats showed that earlier successional stages were considerably warmer than later successional stages, and the distribution of Glanville fritillary larval 'webs' within plots was restricted to these warmer habitats. Hostplants selected for oviposition by gravid females were also considerably warmer than ambient temperature.

The importance of habitat quality reinforces the notion that thermophilous insects would benefit from site management practices that create thermally diverse environments. Heterogeneous habitats provide refugia for species intolerant of climate change, as well as opportunities for range expansion.

\section{Introduction}

Recent projections suggest that the average temperature of the Northern Hemisphere will rise between $0.9-2$ degrees in the next few decades (IPCC 2013). Climate change is considered a significant threat to biodiversity (McLaughlin et al. 2002; Thomas et al. 2004a), although the ecological response to increasing temperatures varies across species groups (Hickling et al. 2006; Chen et al. 2011; Devictor et al. 2012). Insects, which are predominantly ectothermic species with short life cycles, often show rapid and clear responses to changes in temperature (Sinclair et al. 2003; Hassall et al. 2007; Boggs \& Inouye 2012). They are an essential component to the functioning of most terrestrial ecosystems (New 2009; Montoya et al. 2012) and so understanding the key drivers of insect abundance has significant consequences for conservation, agriculture, forestry, diseases, ecosystem services and ultimately humanity (Biesmeijer et al. 2006; Haslett 2008; Potts et al. 2010). Furthermore, with extinction rates in insects exceeding those of plants, birds and mammals (Thomas et al. 2004b; Dunn 2005) clarifying the effect that climate change will have on insect populations remains a priority (Maclean \& Wilson 2011; Pettorelli 2012), and more pertinently, can ambient temperature rise be ameliorated through habitat management (Bourn \& Thomas 2002; Lawson et al. 2012)?

Like most insects, butterflies are extremely sensitive to changes in temperature and are therefore affected strongly by climatic limitations at a range of spatial scales (Dennis \& Shreeve 1991; Bryant et al. 2002; Storch et al. 2003). At the broadest scale, latitude determines the climatic tolerances of species (Gutierrez \& Menendez 1995; Dennis et al. 2008), mainly because the time available in which to complete the life cycle is a primary constraint (Thomas 1993; Oliver et al. 2009). Climate is of such importance that increases in temperature have been observed to increase range and distribution (Davies et al. 2005; Lawson et al. 2012), advance emergence dates (Roy \& Sparks 2000; Sparks et al. 2006) as well as increasing movement (Sparks et al. 2005; Sparks et al. 2007). However, relatively few studies have demonstrated the importance of temperature on abundance (Pollard 1988; Roy et 
al. 2001), and so comprehending the link between temperature and population dynamics of individual species remains poorly understood (WallisDeVries et al. 2011).

Within sites, small variation in vegetation structure and topography creates thermal gradients across the landscape, forming microclimates where patches of ground become considerably hotter or cooler than the ambient temperature (Rosenberg 1974; Suggitt et al. 2011). This is particularly important to butterflies, as the temperature of a hostplant within a microclimate is often a key determinant of larval development rates (Braby \& Jones 1994; Thomas et al. 2011). Therefore, within species, individuals can control for variations in temperature by choosing to oviposit on hostplants on different aspects or within vegetation of different heights (Roy \& Thomas 2003; Dennis 2010). Furthermore, many butterflies at the northern edge of their range therefore survive by inhabiting earlier (hotter) successional stages of habitats opposed to their conspecifics living within the (warmer) centres of their range (Thomas 1993; Thomas et al. 1999), and so the local distribution of higher latitude populations is frequently restricted by warmer microclimates within habitats (Thomas 1995b).

Consequently, within northern Europe the abundance of many butterfly species is correlated with the availability of suitable microclimates or 'habitat quality' within a site (Thomas et al. 2001; Krämer et al. 2012; Eilers et al. 2013). However, temperature driven changes in habitat associations remain poorly understood (Davies et al. 2006; Turlure et al. 2010), yet comprehending such changes are essential for adaptive conservation management (Sutherland 1998; Roy \& Thomas 2003). Therefore, an important unanswered question is whether temporal variation in habitat quality, or ambient temperature is the stronger predictor in determining species abundance. Put simply, the conservation advice of creating habitat mosaics, which provide a variety of microclimates to facilitate oviposition requirements for many species, is widely regarded as a management panacea to compensate against temperature fluctuations ( supporting this strategy remains circumstantial.

The Glanville fritillary Melitaea cinxia is an excellent model for testing the role of both weather and habitat quality on abundance. It is a monophagous and highly thermophilous species: in the UK it is restricted to early-successional habitat on south-facing slopes at the southern edge of the country (Asher et al. 2001), so we expect it to be extremely sensitive to changes in temperature (Diamond et al. 2011). Research on the Glanville fritillary within the U.K., has demonstrated that females are highly selective and choose to oviposit only on the smallest plants in warm microhabitats (Thomas et al. 2001) and furthermore habitat quality (the availability of preferred hostplants in suitable condition) explains spatial variation in both distribution and abundance. Moreover, in Finland, where 
the Glanville fritillary has been a model for developing and testing metapopulation theory (Hanski $\underline{1998)}$ ), there is strong evidence linking population status with summer droughts ( 2005; Ojanen et al. 2013).

Here we compare temporal variation in both weather variables and habitat quality to assess which is the stronger predictor of inter-annual variation in abundance on an individual site, and whether the temperature of microhabitats varies depending on the height of vegetation above it, using data gathered over 14 years from one population.

\section{Methods}

\section{Study species}

The Glanville fritillary is a univoltine species in the U.K., with a typical flight period lasting from May to July. Eggs are laid in clusters on the underside of a Ribwort Plantain Plantago lanceolata leaf, with most oviposition occurring in June. During summer the larvae live and feed gregariously and spin a silken web around the plantain leaves. They enter diapause within the web during early autumn, and emerge the following spring, when they again feed communally and spin a conspicuous web around plantains before pupating in April.

\section{Study site \& vegetation survey}

Binnel Point is approximately $2.5 \mathrm{~km}$ east of the southern tip of the Isle of Wight, just south of the village of St Lawrence. It supports a relatively small population of Glanville fritillaries and is isolated from the next nearest population (St Catherine's Point) by over $2 \mathrm{~km}$. The site is predominantly mesotrophic grassland on the cliff edges flanked on the northern edge by thick scrub. The area used for breeding and oviposition by Glanville fritillaries remains extremely small with the cliff top grassland habitat covering an area of approximately $200 \mathrm{~m} \times 20 \mathrm{~m}$, with a total study area of 0.4 hectares (Figure 1).

To test the importance of habitat quality on larval web numbers, the study area was divided into adjacent plots which were easily identifiable on repeated surveys (Figure 1); Two of the plots were of similar size but of opposing aspect, separated by a smaller (flat) plot, and the remaining two plots were smaller, contiguous and south-facing (Table 1).

The abundance of larval webs at this site was monitored from 1996-2013. During the 14 of these years (1997-2010) RJC conducted a matching survey of the habitat quality. At each survey, plots 
were scored by the percentage cover in five categories (successional stages from bare ground to long grass) based on the amount of bare ground and mean turf height (Table 2). These data were converted into estimates of habitat quality by multiplying the area in each category by the habitat preference score for that category. Habitat preference scores are the relative probabilities of occurrence within each habitat type, summed to 1 . We used scores derived from Thomas et al (2001), who compared the distributions of 368 larval webs and hostplants among five habitat categories, each representing a different successional stage.

These estimates of quality were used to assess the strength of relationship between the amount of suitable habitat and butterfly abundance.

\section{Local Temperature Data}

The temperature beneath the various successional stages of habitats (see Table 2 for definitions) was recorded by five Tiny tag temperature loggers placed beneath the soil surface, with another recording ambient air temperature from 15th to 17th May 1998 (Figure 2).

A hand held laser thermometer was also used to record hostplant temperatures that were utilised for oviposition (Figure 3). Temperatures were acquired by following 60 gravid females during $6^{\text {th }}-$ $25^{\text {th }}$ June 2010 and recorded whilst oviposition was occurring. A note was made of time of oviposition, and this time was then matched to ambient temperature of a Tiny tag data logger which was set to record ambient air temperature every five minutes during the same day. If times did not exactly match then differences of two minutes or less were rounded down to the nearest five minute recording, and three minutes and above were rounded up to the next recording. Air temperatures varied very little between five minute intervals.

\section{Regional Weather Data}

Weather data were obtained from the nearest Meteorological Office station, which was just over $2 \mathrm{~km}$ from Binnel Point (St Catherine's Point Lighthouse SZ497753). We used June mean maximum temperature (i.e. the mean of the daily maxima) and July rainfall to assess the relationship between temporal variation in weather and butterfly abundance. Mean maximum June temperature is a good measure of the warmth of June days, which is when most eggs are laid. July rainfall was found to be important for Glanville fritillary population dynamics in Finland (Hanski \& Meyke 2005; Ojanen et al. $\underline{2013}$ ), as host plants withered during dry summers, thus increasing larval mortality.

\section{Statistical Analysis}


The data used in this analysis was derived from 14 years of surveys across 5 habitat plots: thus $14 \times 5$ = 70 web counts: one for each year - plot combination, each of which has a matching estimate of habitat quality.

Glanville fritillary abundance (number of webs) was modelled as a function of habitat quality (from the same year) and June temperatures and July rainfall (of the previous year, when those eggs were laid), in a multi-predictor GLM with quasipoisson errors (since the abundance estimates were overdispersed) and $\log$ (plot area) as an offset. Plot identity was included as a categorical 'nuisance variable' (to control for variation among plots), consequently our model examines the relative effects of changes in temperature and habitat quality through time. Significance was assessed by removing terms and comparing the goodness-of-fit of nested models using Chi-squared, with $\alpha=0.05$. We estimated the effect size for each predictor variable as the fitted difference in web numbers over the observed range of variation of that predictor. All models were fitted in $R$ ( $\underline{R}$ Development Core Team 2010).

\section{Results}

\section{Habitat microclimate temperatures}

There is a clear decrease in ground temperature between the earliest successional stage (1) and the last (5) of approximately two degrees per stage around the warmest time of day - midday (Figure 2). The preferred larval habitat categories observed by Thomas et al (2001) ( 2 and 3, see Table 2) are eight and ten degrees warmer than ambient air temperature.

\section{Hostplant temperatures}

Mean temperature of hostplants during oviposition was 27.70 degrees Celsius (S.D $=3.47$, Figure 3 ). Although not directly compared with hostplants on which oviposition did not occur, simultaneous ambient air temperature was just 19.79 degrees $(S . D=1.64)$. The difference is highly significant: $t$ $(59)=20.754, p=<0.001$.

The temperature of plants on which females were observed to oviposit was therefore on average eight degrees hotter than ambient air temperatures. Thus, Glanville fritillary females show a clear preference for hostplants which are significantly hotter than ambient temperatures.

\section{Correlates of Population Abundance}

There is a strong and significant role for both changes in habitat quality (Figure 4) and temperature (Figure 5). Web counts were significantly higher following relatively warm June weather of the 
previous year $(b=0.935, \mathrm{se}=0.166, t=5.63, p<0.001)$ and when large areas of high quality habitat were available $(b=0.103, s e=0.04, t=2.819, p<0.05)$. Both temperature and habitat quality are independent effects, with no significant relationship between the two parameters $(p=0.25)$. We found no evidence for a relationship between abundance and rainfall in the previous July $\left(\chi^{2}=0.58, p=0.45\right)$.

To compare the effect sizes of temperature and habitat quality, we estimated the difference in fitted abundance across the range of observations for both temperature and habitat quality. For temperature, the parameter estimate means that each degree of warmth is associated with an increase in web counts by a factor of $\mathrm{e}^{0.935}=2.5$. Thus, across the range of temperatures observed ( 2.2 degrees $C$ ), the fitted difference in abundance varies by $\mathrm{e}^{(0.935 \times 2.2)}=7.83$ fold from the coldest to warmest years. Each point increase (percentage) on the habitat quality scale is associated with an increase of webs by $e^{0.103}=11 \%$, and across the range of qualities $(0-25.65)$ the fitted difference in abundance varies by $\mathrm{e}^{(0.103 \times 25.65)}=14.04$ fold from the poorest to highest quality habitats.

Therefore, the fitted differences in abundance would suggest that on average, habitat quality is almost twice as important as temperature in determining temporal butterfly abundance.

\section{Discussion}

We found that both temporal changes in habitat quality (percentage of warmer microclimates present within each plot) and ambient air temperature were highly significant in determining Glanville fritillary abundance. However, habitat quality was almost twice as important as ambient temperature, suggesting a key role for management of habitat microclimates to ameliorate the impact of climate warming.

\section{Microclimate}

Temperatures recorded by the Tiny tag data loggers (Figure 2), demonstrate the differences in ground temperatures between successional stages (depending on the height of vegetation and the amount of bare ground).

The combined evidence of strong larval microhabitat preferences (Thomas et al. 2001) and our recorded microclimate temperatures (Figure 2) suggests that temperature is a key factor in explaining suitability of oviposition localities and thus distribution of larval webs within habitats. Eggs are probably laid on hostplants within these warmest habitats to maximise thermoregulation and metabolic efficiency, thus expediting development time (Bryant et al. 2002). 
Although the earliest successional stage (1) is the warmest (Figure 2), this stage is predominantly bare ground interspersed with very short turf. The preference for habitat successional stage 2 can be understood as the warmest stage which provides a sward structure capable of supporting a larval web complete with inner chambers, and more importantly a hibernaculum which is essential for overwintering survival. Furthermore, temperature demarcation above habitat stage 2 is so acute, that hostplants are unlikely to be of a suitably warm temperature (and thus utilised), unless they are within locations which are warm for reasons other than habitat structure, for example, because they are sheltered due to topography or on south facing slopes.

\section{Selection of Hostplants}

Female Glanville fritillaries show a clear preference for hostplants which are considerably warmer (on average 8 degrees) than the ambient air temperature (Figure 3). Again, this is because the temperature of a hostplant is crucial to optimise larval development (Renwick \& Chew 1994; Doak et al. 2006). Therefore, as the Glanville fritillary is at the northern edge of its distribution within the U.K., females will invest considerable effort in finding suitably warm locations for oviposition which will expedite larval growth and maximise chances of successful development (Thomas 1991; Merrill et al. 2008).

\section{Habitat Quality}

Habitat quality is an important determinant of butterfly abundance, which increases 14 fold from the worst habitats to the best (or $10 \%$ with each point increase on the habitat quality scale). Plots with greater spatial extent of warmer successional stages (both within and between years) are thus more likely to contain higher numbers of Glanville fritillary larval webs.

Furthermore, the abundance of many butterfly species within the U.K are likely to increase with the availability of early successional habitats, given that they are often restricted to warmer microclimates within habitats (Thomas 1993). Hence, the lack of management within sites can often explain the demise of many thermophilous butterfly species (Thomas 1991), and the initiation of appropriate management within sites can also explain the dramatic recovery of others (Thomas 1983, 1995a; Thomas et al. 2011).

\section{Ambient Temperature}

Glanville fritillary abundance is highly correlated with temperature in the previous June, i.e. when the eggs were laid. This result is further evidence that oviposition is temperature-dependent: in warm years a greater proportion of plantains are within the thermal envelope for oviposition (Weiss 
et al. 1988; Roy \& Thomas 2003), but in cold years females restrict their egg-laying to a small proportion of the available plantains. The most likely mechanism linking temperature to abundance is therefore the amount of hostplants within a suitably warm microclimate, but we cannot rule out the possibility of density-dependent larval mortality (Hanski et al. 1996; Nowicki et al. 2009) or that fecundity itself might be temperature dependent (Saastamoinen 2007; Ojanen et al. 2013).

Our result also explains why species at northern limits of their range often experience dramatic population fluctuations (Thomas et al. 1994; Davies et al. 2006; Oliver et al. 2012a): hostplants on cooler slopes and aspects can be utilised during warm years, resulting in temporary increase in both the abundance of individual populations and the area of occupied habitat.

\section{Recommendations for Site Management}

Both habitat quality and ambient air temperature were highly significant in determining Glanville fritillary abundance. However, habitat quality within sites was almost twice as important as ambient temperature, suggesting a key role for management of habitat microclimates to ameliorate the likelihood of increased temperature variability due to climate change (Bergman et al. 2008; Lawson et al. 2012; Eilers et al. 2013).

The options for managing the habitat of Glanville fritillaries in Britain is limited, since most colonies occur on soft cliff habitats (Curtis et al. 2014). Those that do occur on grassland (including Binnel Point) could be managed to create a mosaic of (mainly short) turf interspersed with taller vegetation which provides shelter and structure for hibernacula. More generally, within-site microclimate management could benefit many thermophilous insect species that reach their northern range margin within the U.K., and can explain why inappropriate or lack of management (thereby reducing the spatial extent of early successional or suitably warm habitats) has caused the relatively high losses observed in insects populations compared to other species groups (Thomas \& Morris 1994; Thomas 1995b; Thomas et al. 2004b).

Creating a mosaic of vegetation within sites therefore remains a priority in butterfly conservation, as oviposition sites are often determined by temperature (Shreeve 1986; Dennis 2010; Eilers et al. 2013). Variation in turf heights will provide a degree of flexibility which can counteract ambient temperature fluctuations (Roy \& Thomas 2003; Oliver et al. 2012b) and furthermore, patches of longer turf will provide shelter which can be important during periods of inclement weather (Dennis \& Sparks 2006) and provide oviposition locations for less thermally restricted species thus maximising butterfly diversity within sites (№w 2009). 


\section{Conclusions}

The Glanville fritillary is at the northern edge of its range within the U.K., where temperature is a principle constraint. Most larvae occur in the (earlier) warmer successional stages that have sufficient vegetation to supporting larval web structures.

The Glanville fritillary is extremely sensitive to fluctuations in both the amount of suitably warm habitat within plots and ambient air temperature, and therefore both habitat quality and temperature are highly significant predictors of population abundance.

To maintain long-term population stability and viability within sites, management creating a range of thermally diverse habitats is recommended. Areas which contain more heterogeneous habitats will also allow a degree of flexibility in choice of oviposition locations, in that variations in turf height can counteract year-to-year fluctuations in ambient temperatures. This could be particularly important for conserving insect populations if temperatures continue to increase due to climate warming.

\section{Acknowledgements}

This work as supported by NERC grants NE/D009448/1 and NE/F007930/1. We are also grateful to the Isle of Wight Natural History and Archaeological Society (IWNHAS), Andy Butler, David Simcox, Jeremy Thomas and Wightlink. We thank two anonymous reviewers for constructive comments on a previous version of this manuscript.

\section{References}

Asher J., Warren M., Fox R., Harding P., Jeffcoate G. \& Jeffcoate S. (2001). The Millennium Atlas of Butterflies in Britain and Ireland. Oxford University Press., Oxford.

Bergman K.O., Ask L., Askling J., Ignell H., Wahlman H. \& Milberg P. (2008). Importance of boreal grasslands in Sweden for butterfly diversity and effects of local and landscape habitat factors. Biodiversity and Conservation, 17, 139-153.

Biesmeijer J.C., Roberts S.P.M., Reemer M., Ohlemueller R., Edwards M., Peeters T., Schaffers A.P., Potts S.G., Kleukers R., Thomas C.D., Settele J. \& Kunin W.E. (2006). Parallel declines in pollinators and insect-pollinated plants in Britain and the Netherlands. Science, 313, 351354.

Boggs C.L. \& Inouye D.W. (2012). A single climate driver has direct and indirect effects on insect population dynamics. Ecology Letters, 15, 502-508.

Bourn N.A.D. \& Thomas J.A. (2002). The challenge of conserving grassland insects at the margins of their range in Europe. Biological Conservation, 104, 285-292.

Braby M.F. \& Jones R.E. (1994). Effect of Temperature and Hostplants on Survival, Development and Body-Size in 3 Tropical Satyrine Butterflies from North-Eastern Australia. Australian Journal of Zoology, 42, 195-213.

Bryant S.R., Thomas C.D. \& Bale J.S. (2002). The influence of thermal ecology on the distribution of three nymphalid butterflies. Journal of Applied Ecology, 39, 43-55.

Chen I.-C., Hill J.K., Ohlemüller R., Roy D.B. \& Thomas C.D. (2011). Rapid Range Shifts of Species Associated with High Levels of Climate Warming. Science, 333, 1024-1026. 
Curtis R.J., Botham M.S., Brereton T.M. \& Isaac N.J.B. (2014). The Rise and Demise of the Glanville fritillary on the Isle of Wight. Journal of Insect Conservation, In review.

Davies Z.G., Wilson R.J., Brereton T.M. \& Thomas C.D. (2005). The re-expansion and improving status of the silver-spotted skipper butterfly (Hesperia comma) in Britain: a metapopulation success story. Biological Conservation, 124, 189-198.

Davies Z.G., Wilson R.J., Coles S. \& Thomas C.D. (2006). Changing habitat associations of a thermally constrained species, the silver-spotted skipper butterfly, in response to climate warming. Journal of Animal Ecology, 75, 247-256.

Dennis R.L.H. (2010). A Resource-Based Habitat View for Conservation: Butterflies in the British Landscape. Wiley - Blackwell, Chichester, UK.

Dennis R.L.H., Dapporto L., Shreeve T.G., John E., Coutsis J.G., Kudrna O., Saarinen K., Ryrholm N. \& Williams W.R. (2008). Butterflies of European islands: the implications of the geography and ecology of rarity and endemicity for conservation. Journal of Insect Conservation, 12, 205236.

Dennis R.L.H. \& Shreeve T.G. (1991). Climatic change and the British butterfly fauna: Opportunities and constraints. Biological Conservation, 55, 1-16.

Dennis R.L.H. \& Sparks T.H. (2006). When is a habitat not a habitat? Dramatic resource use changes under differing weather conditions for the butterfly Plebejus argus. Biological Conservation, 129, 291-301.

Devictor V., van Swaay C., Brereton T., Brotons L., Chamberlain D., Heliola J., Herrando S., Julliard R., Kuussaari M., Lindstrom A., Reif J., Roy D.B., Schweiger O., Settele J., Stefanescu C., Van Strien A., Van Turnhout C., Vermouzek Z., WallisDeVries M., Wynhoff I. \& Jiguet F. (2012). Differences in the climatic debts of birds and butterflies at a continental scale. Nature Clim. Change, 2, 121-124.

Diamond S.E., Frame A.M., Martin R.A. \& Buckley L.B. (2011). Species' traits predict phenological responses to climate change in butterflies. Ecology, 92, 1005-1012.

Doak P., Kareiva P. \& Kingsolver J. (2006). Fitness consequences of choosy oviposition for a timelimited butterfly. Ecology, 87, 395-408.

Dunn R.R. (2005). Modern insect extinctions, the neglected majority. Conservation Biology, 19, 10301036.

Eilers S., Pettersson L.B. \& ÖCkinger E. (2013). Micro-climate determines oviposition site selection and abundance in the butterfly Pyrgus armoricanus at its northern range margin. Ecological Entomology, 38, 183-192.

Gutierrez D. \& Menendez R. (1995). Distribution and Abundance of Butterflies in a Mountain Area in the Northern Iberian Peninsula. Ecography, 18, 209-216.

Hanski I. (1998). Metapopulation dynamics. Nature, 396, 41-49.

Hanski I., Foley P. \& Hassell M. (1996). Random walks in a metapopulation: How much density dependence is necessary for long-term persistence? Journal of Animal Ecology, 65, 274-282.

Hanski I. \& Meyke E. (2005). Large-scale dynamics of the Glanville fritillary butterfly: landscape structure, population processes, and weather. Annales Zoologici Fennici, 42, 379-395.

Haslett J.R. (2008). European strategy for the conservation of invertebrates. Council of Europe.

Hassall C., Thompson D.J., French G.C. \& Harvey I.F. (2007). Historical changes in the phenology of British Odonata are related to climate. Global Change Biology, 13, 933-941.

Hickling R., Roy D.B., Hill J.K., Fox R. \& Thomas C.D. (2006). The distributions of a wide range of taxonomic groups are expanding polewards. Global Change Biology, 12, 450-455.

IPCC (2013). Climate Change 2013: The Physical Science Basis. Working Group I Contribution to the IPCC 5th Assessment Report - Changes to the Underlying Scientific/Technical Assessment (IPCC-XXVI/Doc.4).

Krämer B., Kämpf I., Enderle J., Poniatowski D. \& Fartmann T. (2012). Microhabitat selection in a grassland butterfly: a trade-off between microclimate and food availability. Journal of Insect Conservation, 1-9. 
Lawson C.R., Bennie J.J., Thomas C.D., Hodgson J.A. \& Wilson R.J. (2012). Local and landscape management of an expanding range margin under climate change. Journal of Applied Ecology, no-no.

Maclean I.M.D. \& Wilson R.J. (2011). Recent ecological responses to climate change support predictions of high extinction risk. Proceedings of the National Academy of Sciences, 108, 12337-12342.

McLaughlin J.F., Hellmann J.J., Boggs C.L. \& Ehrlich P.R. (2002). Climate change hastens population extinctions. Proceedings of the National Academy of Sciences of the United States of America, 99, 6070-6074.

Merrill R.M., Gutierrez D., Lewis O.T., Gutierrez J., Diez S.B. \& Wilson R.J. (2008). Combined effects of climate and biotic interactions on the elevational range of a phytophagous insect. Journal of Animal Ecology, 77, 145-155.

Montoya D., Rogers L. \& Memmott J. (2012). Emerging perspectives in the restoration of biodiversity-based ecosystem services. Trends in Ecology \& Evolution, 27, 666-672.

Morecroft M.D. (2012). Adapting conservation to a changing climate. Journal of Applied Ecology, 49, 546.

New T. (2009). Insect Species Conservation. Cambridge University Press.

Nowicki P., Bonelli S., Barbero F. \& Balletto E. (2009). Relative importance of density-dependent regulation and environmental stochasticity for butterfly population dynamics. Oecologia, 161, 227-239.

Ojanen S.P., Nieminen M., Meyke E., Pöyry J. \& Hanski I. (2013). Long-term metapopulation study of the Glanville fritillary butterfly (Melitaea cinxia): survey methods, data management, and long-term population trends. Ecology and Evolution, 3, 3713-3737.

Oliver T., Hill J.K., Thomas C.D., Brereton T. \& Roy D.B. (2009). Changes in habitat specificity of species at their climatic range boundaries. Ecology Letters, 12, 1091-1102.

Oliver T.H., Roy D.B., Brereton T. \& Thomas J.A. (2012a). Reduced variability in range-edge butterfly populations over three decades of climate warming. Global Change Biology, 18, 1531-1539.

Oliver T.H., Thomas C.D., Hill J.K., Brereton T. \& Roy D.B. (2012b). Habitat associations of thermophilous butterflies are reduced despite climatic warming. Global Change Biology, n/an/a.

Pettorelli N. (2012). Climate change as a main driver of ecological research. Journal of Applied Ecology, 49, 542-545.

Pollard E. (1988). Temperature, rainfall and butterfly numbers. Journal of Applied Ecology, 25, 819828.

Potts S.G., Biesmeijer J.C., Kremen C., Neumann P., Schweiger O. \& Kunin W.E. (2010). Global pollinator declines: trends, impacts and drivers. Trends in Ecology \& Evolution, 25, 345-353.

R Development Core Team (2010). R: A Language and Environment for Statistical Computing. In. R Foundation for Statistical Computing Vienna, Austria.

Renwick J.A.A. \& Chew F.S. (1994). Oviposition Behavior in Lepidoptera. Annual Review of Entomology, 39, 377-400.

Rosenberg N.J. (1974). Microclimate:the biological environment. Wiley.

Roy D.B., Rothery P., Moss D., Pollard E. \& Thomas J.A. (2001). Butterfly numbers and weather: predicting historical trends in abundance and the future effects of climate change. Journal of Animal Ecology, 70, 201-217.

Roy D.B. \& Sparks T.H. (2000). Phenology of British butterflies and climate change. Global Change Biology, 6, 407-416.

Roy D.B. \& Thomas J.A. (2003). Seasonal variation in the niche, habitat availability and population fluctuations of a bivoltine thermophilous insect near its range margin. Oecologia, 134, 439444.

Saastamoinen M. (2007). Life-history, genotypic, and environmental correlates of clutch size in the Glanville fritillary butterfly. Ecological Entomology, 32, 235-242. 
Shreeve T.G. (1986). Egg-laying by the speckled wood butterfly (Pararge aegeria): the role of female behaviour, host plant abundance and temperature. Ecological Entomology, 11, 229-236.

Sinclair B.J., Vernon P., Jaco Klok C. \& Chown S.L. (2003). Insects at low temperatures: an ecological perspective. Trends in Ecology \& Evolution, 18, 257-262.

Sparks T.H., Dennis R.L.H., Croxton P.J. \& Cade M. (2007). Increased migration of Lepidoptera linked to climate change. European Journal of Entomology, 104, 139-143.

Sparks T.H., Huber K. \& Dennis R.L.H. (2006). Complex phenological responses to climate warming trends? Lessons from history. European Journal of Entomology, 103, 379-386.

Sparks T.H., Roy D.B. \& Dennis R.L.H. (2005). The influence of temperature on migration of Lepidoptera into Britain. Global Change Biology, 11, 507-514.

Storch D., Konvicka M., Benes J., Martinkova J. \& Gaston K.J. (2003). Distribution patterns in butterflies and birds of the Czech Republic: separating effects of habitat and geographical position. Journal of Biogeography, 30, 1195-1205.

Suggitt A.J., Gillingham P.K., Hill J.K., Huntley B., Kunin W.E., Roy D.B. \& Thomas C.D. (2011). Habitat microclimates drive fine-scale variation in extreme temperatures. Oikos, 120, 1-8.

Sutherland W.J. (1998). Conservation science and action. Blackwell Science.

Thomas C.D., Cameron A., Green R.E., Bakkenes M., Beaumont L.J., Collingham Y.C., Erasmus B.F.N., de Siqueira M.F., Grainger A., Hannah L., Hughes L., Huntley B., van Jaarsveld A.S., Midgley G.F., Miles L., Ortega-Huerta M.A., Peterson A.T., Phillips O.L. \& Williams S.E. (2004a). Extinction risk from climate change. Nature, 427, 145-148.

Thomas J., Simcox D. \& Hovestadt T. (2011). Evidence based conservation of butterflies. Journal of Insect Conservation, 15, 241 - 258.

Thomas J.A. (1983). The Ecology and Conservation of Lysandra bellargus (Lepidoptera, Lycaenidae) in Britain. Journal of Applied Ecology, 20, 59-83.

Thomas J.A. (1991). Rare species conservation: Case studies of European butterflies. In: The Scientific Management of Temperate Communities for Conservation (eds. Spellerberg IF, Goldsmith FB \& G. MM). Blackwell Oxford, pp. 149 - 197.

Thomas J.A. (1993). Holocene climate changes and warm man-made refugia may explain why a 6th of British butterflies possess unnatural early-successional habitats. Ecography, 16, 278-284.

Thomas J.A. (1995a). The conservation of declining butterfly populations in Britain and Europe: Priorities, problems and successes. Biological Journal of the Linnean Society, 56, 55-72.

Thomas J.A. (1995b). Why Small Cold-Blooded Insects Pose Different Conservation Problems to Birds in Modern Landscapes. Ibis, 137, S112-S119.

Thomas J.A., Bourn N.A.D., Clarke R.T., Stewart K.E., Simcox D.J., Pearman G.S., Curtis R. \& Goodger B. (2001). The quality and isolation of habitat patches both determine where butterflies persist in fragmented landscapes. Proceedings of the Royal Society of London Series BBiological Sciences, 268, 1791-1796.

Thomas J.A. \& Morris M.G. (1994). Patterns, Mechanisms and Rates of Extinction among Invertebrates in the United-Kingdom. Philosophical Transactions of the Royal Society of London Series B-Biological Sciences, 344, 47-54.

Thomas J.A., Moss D. \& Pollard E. (1994). Increased Fluctuations of Butterfly Populations Towards the Northern Edges of Species Ranges. Ecography, 17, 215-220.

Thomas J.A., Rose R.J., Clarke R.T., Thomas C.D. \& Webb N.R. (1999). Intraspecific variation in habitat availability among ectothermic animals near their climatic limits and their centres of range. Functional Ecology, 13, 55-64.

Thomas J.A., Telfer M.G., Roy D.B., Preston C.D., Greenwood J.J.D., Asher J., Fox R., Clarke R.T. \& Lawton J.H. (2004b). Comparative losses of British butterflies, birds, and plants and the global extinction crisis. Science, 303, 1879-1881.

Turlure C., Choutt J., Baguette M. \& Van Dyck H. (2010). Microclimatic buffering and resource-based habitat in a glacial relict butterfly: significance for conservation under climate change. Global Change Biology, 16, 1883-1893. 
WallisDeVries M.F., Baxter W. \& Van Vliet A.J.H. (2011). Beyond climate envelopes: effects of weather on regional population trends in butterflies. Oecologia, 167, 559-71.

Weiss S.B., Murphy D.D. \& White R.R. (1988). Sun, Slope, and Butterflies: Topographic Determinants of Habitat Quality for Euphydryas editha. Ecology, 69, 1486-1496.

Table 1: Characteristics of plots surveyed at Binnel Point 1997 - 2010.

\begin{tabular}{|c|c|c|}
\hline Plot Number & Aspect & Area $\left(\mathbf{m}^{\mathbf{2}}\right)$ \\
\hline 1 & South & 1175 \\
\hline 2 & None (flat) & 122 \\
\hline 3 & North & 1375 \\
\hline 4 & South & 62 \\
\hline 5 & South & 45 \\
\hline
\end{tabular}


Table 2: Definitions of successional stages contained within a typical succession from bare ground to scrub and habitat preference scores associated with each stage (ㅁter Thomas et al. 2001).

\begin{tabular}{|cccc|}
\hline $\begin{array}{c}\text { Habitat category } \\
\text { (successional stage) }\end{array}$ & $\begin{array}{c}\text { \% Bare } \\
\text { Ground }\end{array}$ & $\begin{array}{c}\text { Mean Turf Height } \\
\text { (cm) }\end{array}$ & $\begin{array}{c}\text { Habitat preference scores } \\
\text { (after Thomas et al. 2001) }\end{array}$ \\
\hline 1 & $>90$ & $<5 \mathrm{~cm}$ & $8 \%$ \\
2 & $90->0$ & $5<15 \mathrm{~cm}$ & $54 \%$ \\
3 & 0 & $15<20 \mathrm{~cm}$ & $35 \%$ \\
4 & 0 & $20-25 \mathrm{~cm}$ & $3 \%$ \\
5 & 0 & $>25 \mathrm{~cm}$ & $0 \%$ \\
\hline
\end{tabular}


Figure 1. A map of study plots surveyed at Binnel Point, on the south coast of the Isle of Wight (inset).

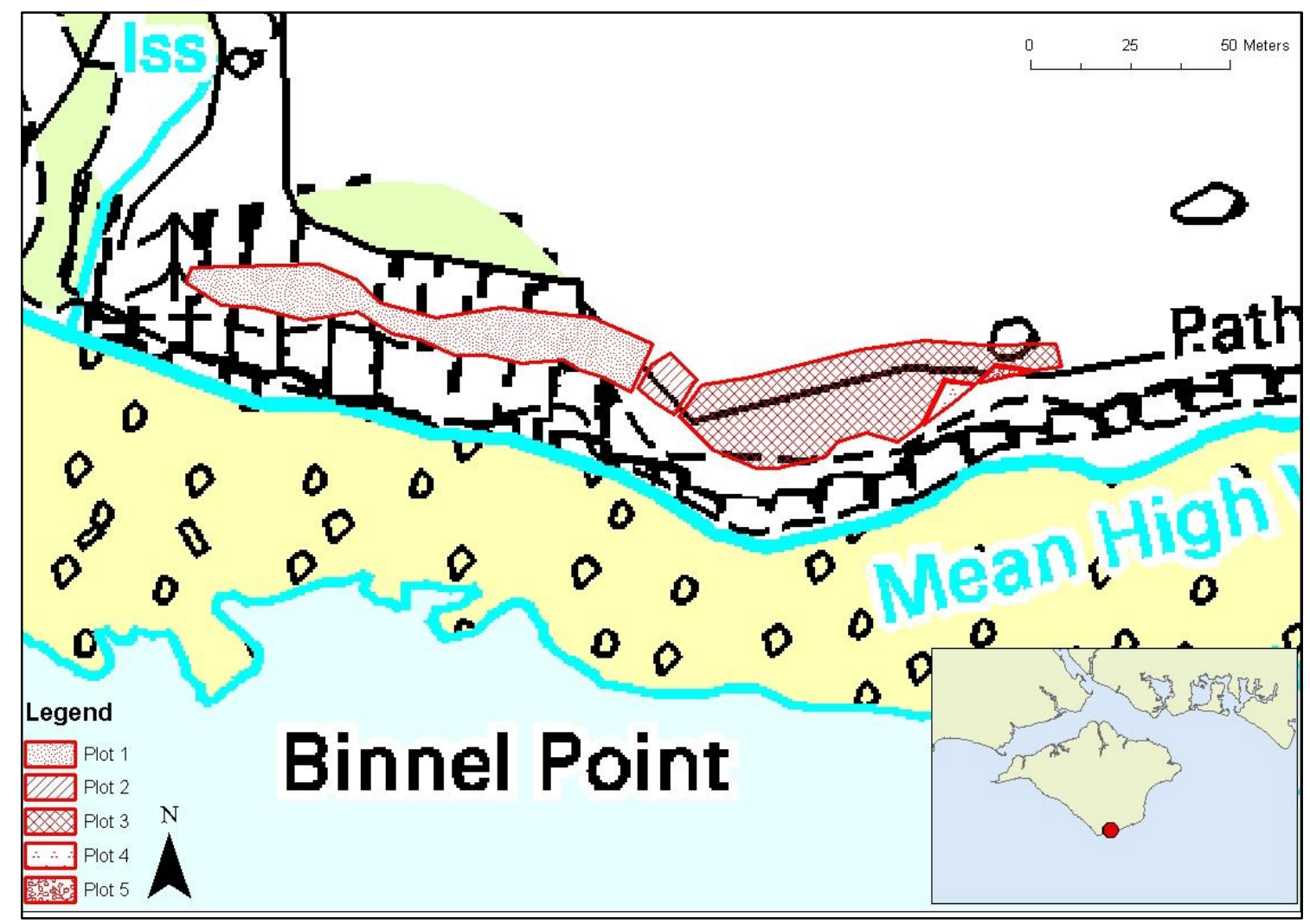

(c) Crown Copyright/database right 2012. An Ordnance Survey/EDINA supplied service. 
Figure 2. A comparison of temperatures between habitat successional stages 1 - 5 (see Table 2), and ambient air temperature over three days in May 1998, recorded by Tiny tag temperature loggers. Habitat 1 is the warmest, followed by 2,3,4, 5 and ambient temperature. Colour references are for the online version only.

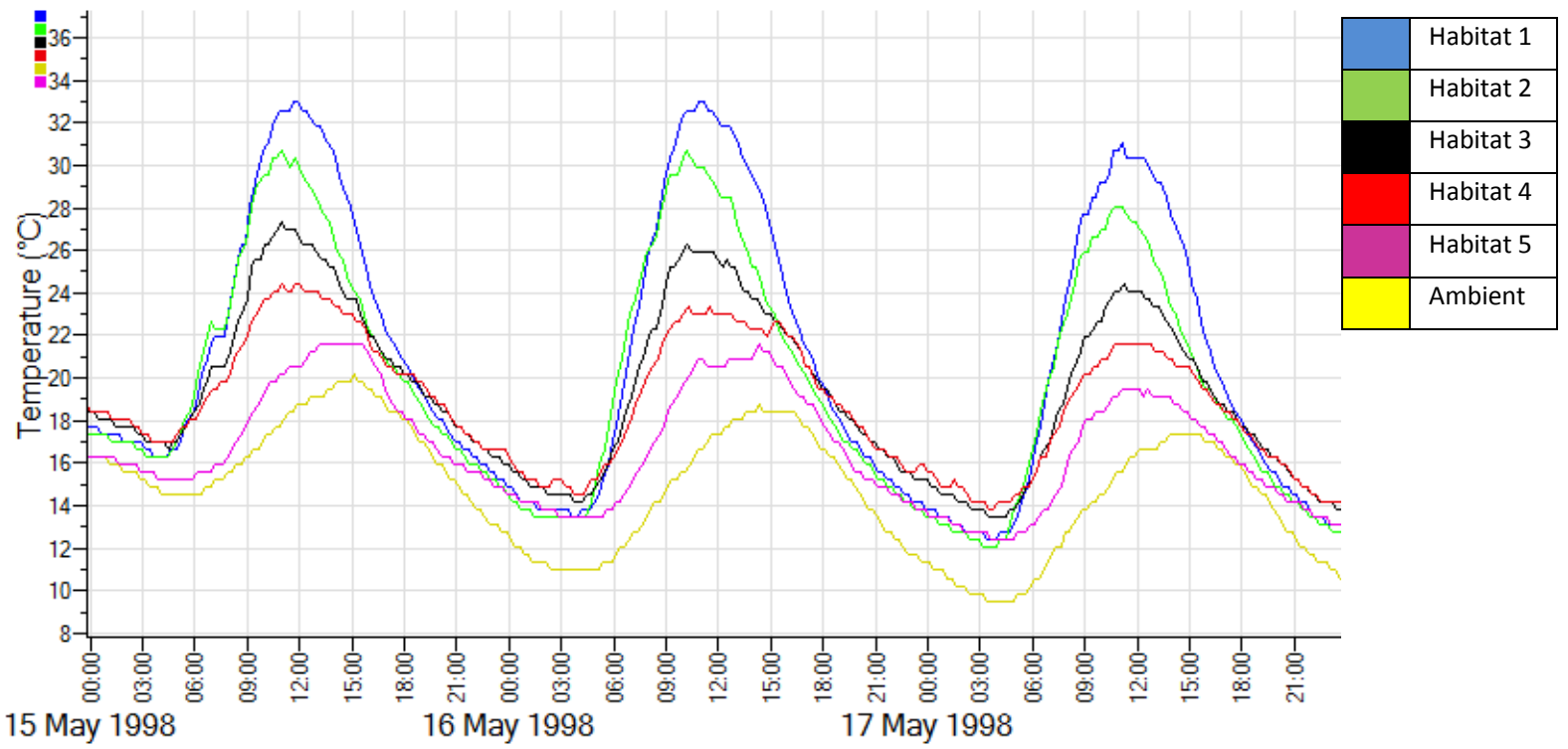


Figure 3. Boxplot illustrating the differences between ambient air temperature recorded by Tiny tag temperature loggers (left) and temperature of a ribwort plantain leaf used for oviposition by the Glanville fritillary (right) recorded using a laser thermometer by following gravid females $(n=60)$. Temperatures were recorded in degrees Celsius on seven dates from 6th - 25th June 2010. Boxplot shows median (thick line), upper and lower quartiles (box), and minimum and maximum values.

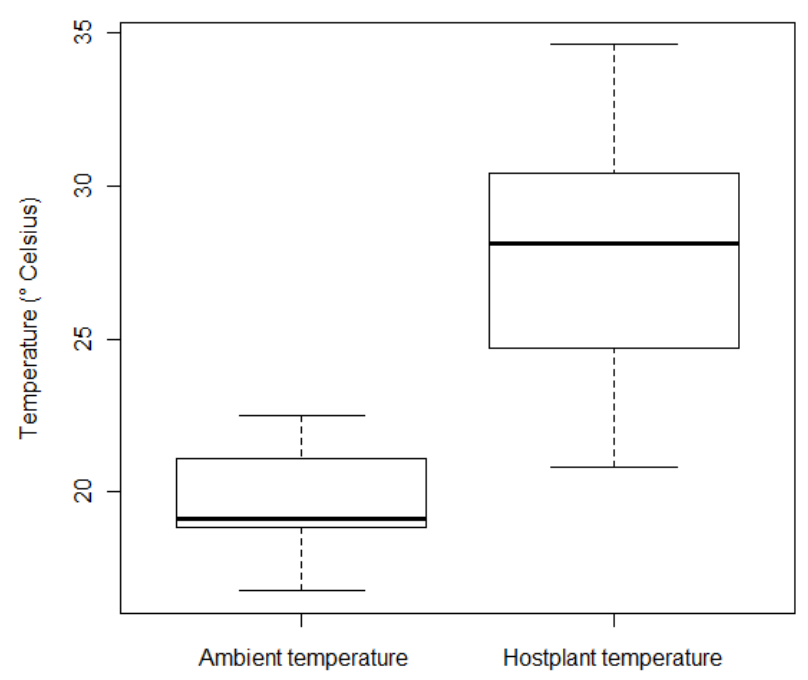


Figure 4. The relationship between web numbers recorded in each plot $\left(\log _{e} X\right)$ and matching estimate of habitat quality from 1997 - 2010 at Binnel Point with least squares regression line.

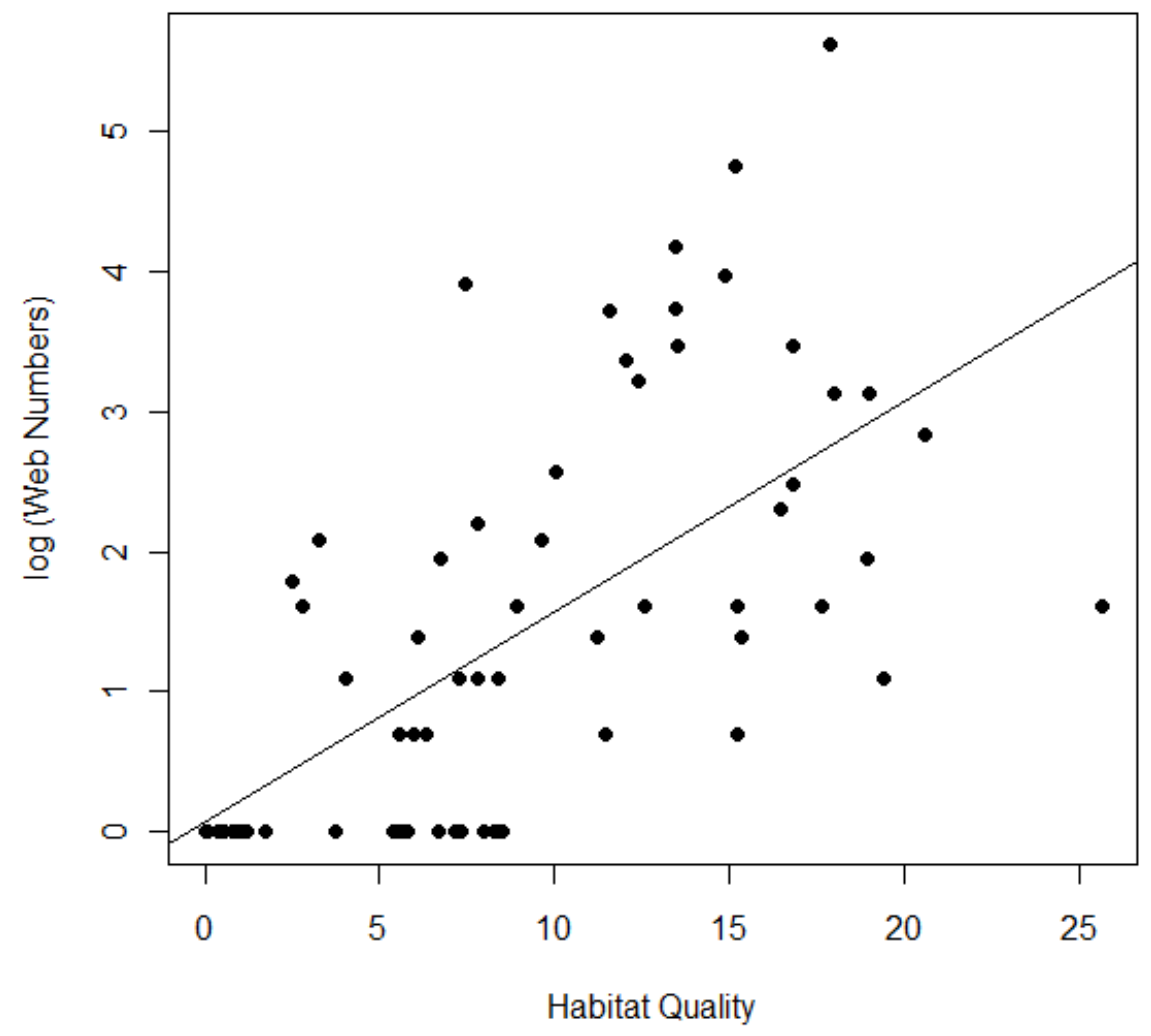


Figure 5. The relationship between web numbers summed across plots $\left(\log _{e} X\right)$ and June mean maximum temperature (degrees Celsius) from 1997 - 2010 at Binnel Point with least squares regression line.

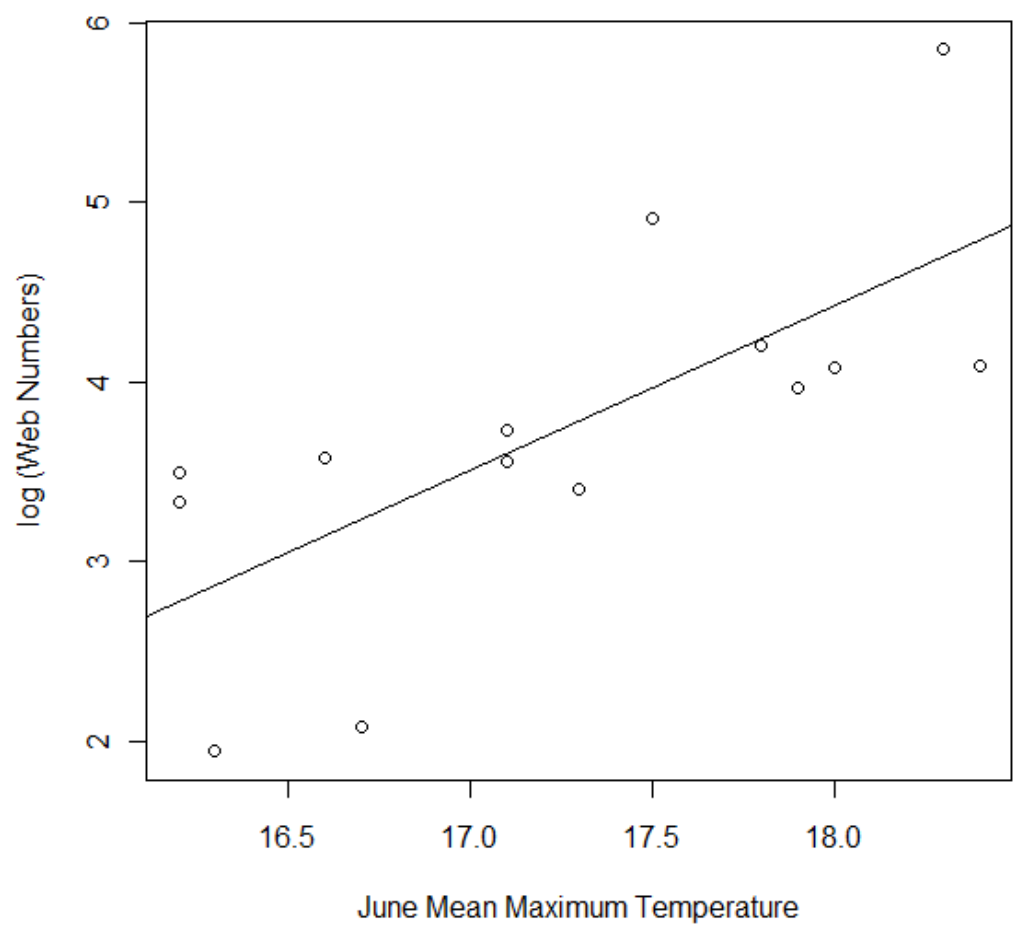

